\title{
La actuación de diplomáticos latinoamericanos en el salvamento de judíos en la Segunda Guerra Mundial
}

The performance of Latin American diplomats in the rescue of Jews during the

\author{
World War II
}

Dr. Efraim Zadoff zadoff@zahav.net.il

Historiador independiente. Miembro de AMILAT.

Traductor, redactor y editor de libros sobre temas judíos en castellano: Enciclopedia de la historia y la cultura del pueblo judio; SHOÁ-Enciclopedia del Holocausto; Dina Porat, Con las manos atadas - El liderazgo sionista y el Holocausto; Yehuda Bauer, Reflexiones sobre el Holocausto.

Rabino laico humanista.

\section{Resumen}

La actitud de los países de América Latina hacia los judíos durante la Shoá se desarrolló a dos niveles: las posibilidades de inmigración que oficial o extraoficialmente brindaron estos países a los refugiados judíos desde 1933 a 1945; el otorgamiento de pasaportes y documentos de protección que podían resguardar a judíos de la persecución, la deportación y el exterminio.

Este trabajo es parte de una investigación más amplia que se ocupa del segundo tema. Generalmente la acción de otorgar pasaportes para salvar judíos fue asumida por algunos 
diplomáticos latinoamericanos sin consultar con sus gobiernos y a veces en contra de su política. Algunos de ellos arriesgaron y perdieron su carrera por esta actuación netamente humanitaria. Hasta el momento se han realizado investigaciones sobre los cónsules de Ecuador, Manuel Antonio Muñoz Borrero; de El Salvador, José Arturo Castellanos, y de Perú, José María Barreto, los tres reconocidos por Yad Vashem como Justos de las Naciones.

Asimismo aquí presento por primera vez el resultado intermedio de mi investigación sobre Samuel del Campo, encargado de negocios y representante de Chile en Rumania. ${ }^{1}$

Mi propósito es el de continuar la investigación para descubrir la actuación de otros cónsules, como Rodolfo Hügli de Paraguay, José Gambetta del Perú, Max Brunner de Haití, Alfonso Bauer de Dominicana, entre otros. Mi intención es la de estudiar y conocer a fondo la actuación de estos cónsules y su contexto, y el de verificar si, al igual que los casos de Muñoz Borrero, Castellanos y Barreto, también a ellos les corresponde una reivindicación y un reconocimiento por su acción en aras de salvar la vida de semejantes.

Palabras clave: Diplomáticos latinoamericanos - Salvamento de judíos - Segunda Guerra Mundial - Holocausto - Pasaportes.

\begin{abstract}
The attitude of Latin America countries towards the Jews during the Shoah took place at two levels: the immigration possibilities -officially or unofficially- that these countries gave to Jewish refugees from 1933 to 1945 ; the granting of passports that could protect Jews from persecution, deportation and extermination.
\end{abstract}

\footnotetext{
${ }^{1}$ Esta investigación aún no ha llegado a término. Aprovecho la oportunidad para agradecer a la Lic. Judith Riquelme por su valiosa ayuda en la consulta de documentos atesorados en el Archivo Histórico del Ministerio del Exterior de Chile.
} 
This work is part of a broader investigation dealing with the second issue. Generally the action of granting passports to save Jews was assumed by some Latin American diplomats without consulting with their governments and sometimes against their policy. Some of them risked and lost his career by this purely humanitarian action. So far this research has been conducted on the consuls from Ecuador, Manuel Antonio Munoz Borrero; from El Salvador, Jose Arturo Castellanos, and Perú, José Maria Barreto, the three recognized by Yad Vashem as Righteous Among the Nations.

Also here I present the intermediate results of my research about Samuel del Campo, business manager and representative of Chile in Romania.

My aim is to continue researching to find out the attitude of other consuls, as Rodolfo Hügli of Paraguay, José Gambetta of Peru, Max Brunner Haiti, Dominican Alfonso Bauer, among others. My intention is to study and get to know the performance of these consuls and their context, to verify whether, as the cases of Munoz Borrero, Castellanos and Barreto, also will have for them a vindication and recognition for their action in order to save lives of fellow human beings.

Keywords: Latin American Diplomats - Rescue of Jews - Second World War - Holocaust Passports.

En las disposiciones de los países de América Latina respecto a los judíos antes, durante y después de la Shoá se pueden distinguir dos tipos de actuación:

1. Referente a la inmigración de refugiados judíos que trataban de huir de Europa, y la actitud a extenderles visas.

2. La posibilidad de protección de víctimas judías por medio de la entrega de documentos de nacionalidad - pasaportes o "promesas". 
Comunemente, en ambos casos, las personas a las que acudían los refugiados eran cónsules -de carrera o honorarios- que se ocupaban de la emisión de la documentación correspondiente. Detrás de ellos, en sus países de origen, estaban la Cancillería y su ministro y jefe de gobierno. Todos ellos eran funcionarios públicos conocidos, que debían cumplir con las instrucciones emitidas por sus gobiernos.

La investigación realizada en las últimas décadas en los archivos diplomáticos de varios países latinoamericanos indica que ninguno de estos países sancionó leyes o decretos que limitaran expresamente la inmigración de judíos. Sin embargo esta restricción existió y fue transmitida como instrucciones de trabajo a los cónsules en Europa ${ }^{2}$. Así es como tenemos en nuestras manos copias de circulares que instruían a los cónsules a investigar detenidamente a los solicitantes de visas y denegárselas en el caso que descubrieran su identidad de judíos. Estas circulares fueron emitidas por las cancillerías de Chile ${ }^{3}$, Argentina $^{4}$, Uruguay ${ }^{5}$, Brasil $^{6}$, Perú $^{7}$, México $^{8}$ y, últimamente, se encontraron también las emitidas por Ecuador ${ }^{9}$ y Paraguay $^{10}$.

\footnotetext{
${ }^{2}$ Ver una reseña general del tema: Avni, H. Los países de América Latina y el Holocausto, en Efraim Zadoff (red.) (2004). SHOÁ - Enciclopedia del Holocausto, pp. 85-94.

${ }^{3}$ Wojak, I. Chile y la inmigración judeo-alemana, en: Avraham Milgram (ed.) (2003). Entre la aceptación y el rechazo - América Latina y los refugiados judíos del nazismo, pp.162-173.

${ }^{4}$ Senkman, L. La cuestión de los refugiados judíos en Argentina y Brasil: la perspectiva de la política internacional y del neutralismo, 1928-1942, en: Avraham Milgram (ed.) (2003). Entre la aceptación y el rechazo - América Latina y los refugiados judíos del nazismo, pp. 37-63.

${ }^{5}$ Raicher, R. (2003). Uruguay, la comunidad israelita y el pueblo judío, pp. 151-155.

${ }^{6}$ Milgram, A. O Itamaraty e os judeus, en: Avraham Milgram (ed.) (2003). Entre la aceptación y el rechazo América Latina y los refugiados judíos del nazismo, pp. 102-117.

${ }^{7}$ Ver Rodríguez, J. (2012). El Tercer Reich visto pot Torre Tagle - Crónicas diplomáticas peruanas de la Segunda Guerra Mundial, Anexo 3 Decreto Supremo del 26 de junio de t936, Limitaciones a la inmigración y a las actividades de los extranjeros en el Perú, pp. 793-796. Ver también cita de Leon Trahtenberg (en una entrevista realizada el 31.3.2005) de una circular interna del Ministerio de Relaciones Exteriores de Perú del 9.9.1938, en: http://www.trahtemberg.com/articulos/669-historia-22-peruanos-murieron-en-auschwitz-.html <ingreso 2.12.2013>.

${ }^{8}$ Gleizer, D. (2000). México frente a la inmigración de refugiados judíos: 1934-1940, pp.123-146.

9 Ver Circular reservada No.10-DC, Ministerio de Relaciones Exteriores de la República de Ecuador, Dirección General de Comercio y de Asuntos Consulares, Quito 29.12.1939; y a ídem, Sección Consular, Circular No. 25-SC19, 8.10.1942, copia de ambas en mi poder. Agradezco a Daniela Dorfzaun haberlas encontrado en el Archivo Histórico del Ministerio en Quito y enviado.

${ }^{10}$ Ver informe del Cónsul General de Suiza en Buenos Aires al Jefe de su Departamento en Berna, 10.4.1940, en Swiss Bundesarchiv (Archivo Nacional suizo), Consulado de Paraguay en Ginebra, E2200.7901\#1970/171\#6*. Ver también carta del Cónsul General del Paraguay en Zúrich al Jefe de la Sección Consular del Ministerio de Relaciones Exteriores, Asunción, 24.5.1941, Archivo Histórico del Ministerio de Relaciones Exteriores, Asunción, Paraguay, DACyL 394.
} 
Sin embargo, y a pesar de estas instrucciones expresas, son conocidos los casos de varios cónsules que emitieron, ya iniciada la guerra, visas de inmigración a judíos. Algunos de ellos lo hicieron eludiendo estas instrucciones o interpretando algunos aspectos de la política de su gobierno e, inclusive, influyendo sobre la misma.

Otros cónsules hicieron lo mismo otorgando un número mayor de visas y arriesgando su posición y su seguridad personal al actuar abiertamente en contra de la política de su gobierno. Uno de los casos es el del embajador brasileño en Francia en 1922-1943, Luis Martins de Souza Dantas, quien emitió cientos de visas diplomáticas a refugiados judíos, contrariando las instrucciones de los funcionarios de su ministerio y del propio ministro Oswaldo Aranha. ${ }^{11}$

Estos casos y muchos otros, tanto los que otorgaron visas, los que las vendieron expoliando a los refugiados o transgrediendo principios morales básicos, y los que las negaron, son conocidos y sus nombres son mencionados en miles de testimonios atesorados en los diversos archivos que se ocupan del tema. ${ }^{12}$

El segundo tipo de actuación se refiere a la entrega de documentos de protección a judíos. El caso más conocido es el de diplomáticos extranjeros en Budapest que salvaron decenas de miles de judíos a partir de octubre de 1944, bajo el gobierno fascista del partido Cruz de Flechas apoyado por los alemanes. Entre los documentos utilizados por estos diplomáticos había miles de pasaportes y certificados de ciudadanía de El Salvador emitidos por su consulado en Ginebra, Suiza, y distribuidos por el cónsul suizo en Budapest Charles Lutz. ${ }^{13}$

Dos casos menos conocidos son los de la utilización de pasaportes como documentos de protección en los países ocupados por los alemanes o en países aliados de los alemanes en los que se aplicaron disposiciones antijudías.

\footnotetext{
${ }^{11}$ Ver SHOÁ - Enciclopedia del Holocausto, p. 457 y Milgram (arriba n. 5), pp. 117-125.

${ }^{12}$ Por ejemplo en el Shoah Foundation Institute for Visual History and Education, (ShFI), University of Southern California, Los Angeles, Estados Unidos.

${ }^{13}$ Sobre este caso ver: Kranzler, D. (2000), The man who stopped the trains to Auschwitz: George Mantello, El Salvador and Switzerland finest hour. El cónsul de El Salvador en Suiza, Cnel. José Arturo Castellanos fue reconocido en mayo de 2010 por Yad Vashem como "Justo de las Naciones". http://www.haaretz.com/jewishworld/salvadoran-diplomat-who-helped-jews-during-holocaust-to-be-named-righteous-gentile-1.290339 $<$ visto 2.12.2013>
} 
El primero de ellos que se presentará a continuación, es el de la utilización de pasaportes y "promesas", que brindaban protección a los judíos que los recibían, convirtiéndolos en posibles candidatos a operaciones de canje de prisioneros entre los Aliados y Alemania. El segundo caso que se presentará más adelante se refiere a la emisión de documentos chilenos en Rumania con el objetivo de proteger a sus portadores de su deportación a Transnistria.

\section{Pasaportes y "promesas" para un posible canje de prisioneros}

Estos documentos que brindaban un cierto tipo de protección, fueron emitidos por diplomáticos latinoamericanos, en su mayoría apostados en Berna y Ginebra, Suiza y en Estocolmo, Suecia, ambos países neutrales durante la guerra. Los pasaportes eran de dos tipos: en forma de libreta, tal como el caso de los de Ecuador, Perú y otros, o una hoja de papel de tamaño oficio, como el caso de Honduras, Paraguay y El Salvador. Ambos tipos de documentos portaban las fotografías de las personas en cuyo nombre se habían emitido, que podía llegar a ser una familia entera en un pasaporte. A veces se les adjuntaba una certificación notarial para que se vean más convincentes.

Las "promesas" eran un documento que certificaba que su portador estaba bajo la protección del país emisor ${ }^{14}$ y que se le había prometido que al presentarse en un consulado de ese país recibiría su pasaporte.

El propósito de estos documentos no era el de permitir la emigración al país emisor sino que servían como documento de protección en las siguientes situaciones:

1. En el comienzo de la ocupación alemana en Europa oriental y la implementación de medidas orientadas a segregar a la población judía, los portadores de documentos extranjeros, entre ellos de países de América Latina, estaban exentos de la obligación de portar un signo distintivo en sus ropas como ser una estrella de David, o de la obligación de permanecer en zonas circunscriptas para judíos - los guetos.

\footnotetext{
${ }^{14}$ La emisión de pasaportes comenzó aparentemente a fines de 1942, en tanto que Alemania prohibió la emigración de los países cuya conquista completó el 23.10.1941.
} 
2. A mediados de 1942, los alemanes decidieron, especialmente en Bélgica y Holanda, que los judíos que no tenían ciudadanía serían los primeros en ser expulsados a campos de exterminio. En esta categoría estaban los judíos alemanes que habían emigrado durante los años '30 y que por las leyes de Nuremberg habían perdido la ciudadanía alemana. Estos documentos les otorgaban una ciudadanía y una eventual protección. $^{15}$

3. A fin de 1942, y con la intención de promover el canje de prisioneros con los Aliados, el departamento legal del Ministerio de Relaciones Exteriores alemán propuso concentrar 30.000 prisioneros que podrían servir como rehenes para el canje por alemanes en poder de los Aliados. Estos alemanes eran prisioneros de guerra como así también alemanes que en el pasado habían emigrado a los países Aliados o a países neutrales, que habían sido recluidos en campos de detención por ser ciudadanos de un país enemigo y que deseaban retornar a la "madre patria". El plan de los 30.000 rehenes, aprobado por el Ministro del Exterior Joachim von Ribbentrop y por el comandante de las SS y Ministro del Interior Heinrich Himmler, consideraba la concentración de judíos con ciudadanía -verdadera o ficticia- de los países Aliados o neutrales. Dada la importancia de estos "rehenes", debían ser mantenidos en condiciones relativamente razonables, infinitamente mejores de las que sufrían la mayoría de los judíos en campos de concentración y trabajos forzados y por supuesto los salvaba de los campos de exterminio. Para este fin fue acondicionado el campo de Bergen Belsen como campo de transición. ${ }^{16}$

El primer transporte de algunos miles de judíos a Bergen Belsen se realizó a mediados de 1943 desde lugares en Polonia en los que se concentraron especialmente judíos con documentos extranjeros: Hotel Polski ${ }^{17}$ en Varsovia y la cárcel de Montelupich en

\footnotetext{
${ }^{15}$ Desde el 30.1.1933 hasta la conquista de Holanda por los alemanes el 10.5.1940, ingresaron al país desde Alemania 33.000 judíos, 15.174 de los cuales aún permanecían en el momento de la conquista. Ver Michman, D. (1978), Los refugiados judíos de Alemania en Holanda en los años 1933-1940 (hebreo), tesis de doctorado, Universidad Hebrea de Jerusalem, pp. 366-367.

${ }^{16}$ Kolb, E. (1990). Bergen Belsen 1943-1945 (hebreo), pp. 18-23.

${ }^{17}$ Shulman, A. (1982). The Case of Hotel Polski - An account of one of the most enigmatic episodes of World War II.
} 
Cracovia $^{18}$. Muchos de ellos portaban pasaportes de Paraguay y Honduras, y en menor cantidad de Ecuador, Perú, Haití y Guatemala, aunque la mayoría tenían "promesas". Las esperanzas despertadas en los judíos que se acercaban a la liberación, se desvanecieron al poco tiempo. En octubre de 1943 las SS requisaron todos los pasaportes para verificar si eran reconocidos por los países emisores. Al comprobar que los países latinoamericanos no los reconocían, casi todos fueron enviados a Auschwitz. Sólo 350 se salvaron de esa deportación y permanecieron en Bergen Belsen.

El mismo proceso sufrieron los judíos que fueron enviados desde el sur de Polonia al centro turístico de Vittel en el noreste de Francia. En noviembre de 1943 las SS requisaron sus pasaportes y aguardaron hasta abril de 1944 para recibir el reconocimiento de los diferentes países. Finalmente, al no recibir este reconocimiento, fueron despachados a Auschwitz en mayo de ese año. ${ }^{19}$

Paralelamente a estas acciones, de enero a septiembre de 1944, los alemanes enviaron a Bergen Belsen desde el campo de tránsito de Westerbork en Holanda, 3.670 judíos con pasaportes latinoamericanos y otros documentos, que fueron internados en la sección Campo Estrella (Sternlager). Su destino fue menos desgraciado que el de los demás y algunos cientos lograron ser canjeados por alemanes o sobrevivieron la derrota nazi.

Esto se debe al cambio en la política de Estados Unidos y, en consecuencia, de los países de América Latina, respecto al reconocimiento de estos pasaportes y a la posibilidad de realizar un canje de prisioneros. El marco en el cual se tomaron las decisiones fue el Comité Asesor de Emergencia de Defensa Política de las Américas, en cuya sesión de mayo de 1943 en Montevideo, se decidió que no se reconocerían estos documentos ni se realizaría canje de prisioneros dado que no querían recibir refugiados. Detrás de esta decisión, además del mencionado rechazo por parte de estos países a la inmigración de

\footnotetext{
${ }^{18}$ Ver testimonio 40851 de Louise Gruner Gans, en ShFI, cuya familia recibió en el gueto de Cracovia un pasaporte de Honduras.

${ }^{19}$ Ver lista de nombres de los deportados de Vittel y de Francia en general, en Serge y Beate Klarsfeld (1978), Memoria de la deportación de los judíos de Francia.
} 
judíos, estaba también la posición de Gran Bretaña y Estados Unidos contraria al traslado de mano de obra calificada a Alemania y la de recibir refugiados. ${ }^{20}$

La modificación mencionada en esta política comenzó con el cambio que se registró en Estados Unidos a comienzos de 1944 respecto a los judíos, a pesar de la política llevada por el Departamento de Estado. En el mes de enero se establecó el WRB - Consejo de Refugiados de Guerra (War Refugees Board) que intentó ayudar en el salvamento de refugiados judíos. Este cambio fue acompañado de una nueva decisión del Comité Asesor de Emergencia del 31.5.1944 que reconocía a estos pasaportes como documentos de protección pero con la condición expresa de que no sirvieran para la inmigración al país emisor. Esta decisión y la disposición al canje de rehenes fueron las que permitieron la negociación a fines de 1944 que condujo a un canje en enero de 1945.

\section{Origen de los documentos}

Los pasaportes latinoamericanos fueron conseguidos o adquiridos en consulados de países latinoamericanos en Berna y Ginebra, en Estocolmo, en Lisboa y, en algunos casos, en Estados Unidos y algunos países de América Latina. Los países en cuyo nombre se emitieron fueron: Paraguay, Honduras, El Salvador, Ecuador, Guatemala, Nicaragua, Perú, Haití, Venezuela, Costa Rica y tal vez algún otro.

\section{Pasaportes de Ecuador}

El caso de los pasaportes de Ecuador fue objeto de la primera parte de esta investigación. Los pasaportes fueron emitidos por el Dr. Manuel Antonio Muñoz Borrero, designado cónsul de Ecuador en Estocolmo en 1931. Cuatro años más tarde su posición cambió a la de Cónsul Honorario. El 6.2.1942 Muñoz Borrero fue despedido de su cargo por haber emitido pasaportes ecuatorianos a un grupo de judíos y no judíos en Polonia y nunca pudo retornar a sus funciones en el servicio exterior de su país.

\footnotetext{
${ }^{20}$ Morse, A. (1998). While Six Million Died - A Chronicle of American Apathy, pp. 343-345. Max Paul Friedman, 'The U.S. State Department and the Failure to Rescue: New Evidence on the Missed Opportunity at Bergen-Belsen", Holocaust and Genocide Studies, 19:1, Spring 2005, pp. 26-40, sp. p. 40.
} 
Su despido se debe a un hecho registrado durante la primera mitad de 1941. En esos meses, la compañía naviera sueca Johnson Line negoció con un grupo de 80 polacos residentes en la zona ocupada por la Unión Soviética y con Muñoz Borrero, con el consentimiento de su gobierno, la posibilidad de la inmigración de este grupo a Ecuador y, aparentemente, llegaron a un acuerdo positivo. Dado que este grupo carecía de pasaportes con los cuales conseguir las visas de tránsito correspondientes, Muñoz Borrero envió a Estambul, donde estaba el representante del grupo, 100 pasaportes firmados para que allí completen los nombres y fotos de los pasajeros. Por un mal entendido en el que estuvieron involucrados diplomáticos chilenos, la información sobre el envío de estos pasaportes llegó a la cancillería en Quito. Acto seguido, el Ministerio del Exterior de Ecuador despidió a Muñoz Borrero sin querer atender a sus razones para este procedimiento.

El gobierno sueco, tras recibir el anuncio de este despido en febrero de 1942, no tomó ninguna medida contra Muñoz Borrero, a pesar de la solicitud en este sentido por parte del gobierno ecuatoriano y le permitió continuar en sus funciones. Aparentemente, fue en la primera mitad de 1943 que Muñoz Borrero utilizó los pasaportes que recibió de vuelta de Estambul, y los emitió como documentos de protección para judíos residentes en Polonia y en Holanda. Esta fecha coincide con la época en que los alemanes decidieron implementar el plan de concentrar rehenes en Bergen Belsen.

Esta acción de Muñoz Borrero fue motivada, aparentemente, por la solicitud de un grupo de activistas judíos locales para que emita pasaportes como documentos de protección para judíos en peligro. Entre estos activistas estaban el rabino Abraham Israel Jacobson y un grupo de empresarios, entre ellos Jacob Ettlinger, Fritz Hollander, Moritz Pineas y John Benzian. Probablemente, la idea de utilizar pasaportes como documentos de protección surgió al conocer la actuación en Suiza de organizaciones judías como el Vaad Hahatzalá de la organización judía ortodoxa Agudat Israel, la Agencia Judía, la organización RELICO que era apoyada por el Congreso Judío Mundial y dirigida por Abraham Silberschein y la organización techo de movimientos juveniles sionistas pioneros - Hejalutz, cuyo representante en Suiza era Natán Schwalb. 
En primera instancia los destinatarios de estos pasaportes fueron judíos en Polonia que a mediados de 1943, tras el aniquilamiento del gueto de Varsovia, fueron concentrados en el Hotel Polski en esa ciudad y posteriormente transportados a Bergen Belsen como se mencionó arriba. De estas personas casi no hubo sobrevivientes y no se encontraron listas de los mismos, por lo que no se puede saber pasaportes de qué países ellos portaban. La situación es diferente respecto al grupo de poco más de 300 judíos deportados a Vittel. En la lista detallada de nombres y nacionalidades están registradas 10 personas con pasaportes de Ecuador emitidos por Muñoz Borrero.

En diciembre de 1943 las SS requisaron los pasaportes para verificar su validez y permitieron a estos judíos dirigirse a familiares, a instituciones judías en el mundo y al gobierno polaco en el exilio residente en Londres, para que intercedieran ante los gobiernos latinoamericanos a favor de un reconocimiento de estos documentos. También el gobierno de Estados Unidos, que en tanto había cambiado su política respecto al canje de rehenes y el salvamento de judíos, influyó sobre estos gobiernos y sobre la mencionada nueva decisión de Montevideo del 31.5.1944. ${ }^{21}$ Los gobiernos de Paraguay y luego de Ecuador, reconocieron la validez de estos pasaportes a partir de marzo o abril de ese año, pero procedimientos burocráticos por parte de estos países, y de España y Suiza, que actuaban como países representantes de los mismos, impidieron que este reconocimiento arribe antes de fines de mayo, fecha en la que estos judíos ya habían sido asesinados en Auschwitz. ${ }^{22}$

El segundo grupo que recibió pasaportes de Ecuador lo componían judíos alemanes emigrados a Holanda que carecían de ciudadanía. La protección que les brindaban los pasaportes los eximía de portar la estrella de David amarilla sobre sus ropas, los protegía en los dos primeros años de ocupación de la deportación al campo de trabajos forzados Vught en Holanda y a campos de exterminio. ${ }^{23}$ Finalmente les permitió ser elegidos para el envío al campo de Bergen Belsen, donde alojaban a prisioneros para el canje, en vez del campo de exterminio Auschwitz. De los 3.670 prisioneros transportados a Bergen Belsen desde

\footnotetext{
${ }^{21}$ British National Archives (BNA), FO 371/42871.

${ }^{22}$ A.W. Randall to Brotman, Board of Deputies of British Jews, BNA, FO 371/42755/6499, 14.4.1944.

${ }^{23}$ Ver por ejemplo los testimonios de Vera Schlamm, ShFI 5239 y Helen Simon, ShFI 18838.
} 
Westerbork entre febrero y agosto de 1944, 96 lograron este destino gracias a pasaportes emitidos por Muñoz Borrero.

Este fue el único grupo que tuvo la oportunidad de salvar sus vidas gracias a estos documentos. El cambio mencionado en la política de los países americanos respecto al canje de prisioneros y al interés en salvar algunas vidas de judíos, promovieron las negociaciones entre los Aliados y Alemania nazi. ${ }^{24}$ Por su parte el gobierno de Ecuador accedió a no cancelar públicamente estos pasaportes y permitir su utilización como documentos de protección, no sin antes puntualizar que sus poseedores no se acreditarían a recibir visas de inmigración a ese país y debían entregar los pasaportes ni bien fueran liberados.

Finalmente, en enero de 1945 se llevó a cabo un canje de rehenes entre Alemania y los Aliados. Un tren con 301 judíos con pasaportes latinoamericanos, entre los cuales 69 portaban pasaportes de Ecuador, partió el 21.1.1945 de Bergen Belsen. Aparentemente 176 de ellos, incluyendo 31 con pasaportes de Ecuador, fueron obligados a descender antes de cruzar la frontera con Suiza debido a su estado de salud, y se los trasladó a los campos de Biberach y Wurzach en el sur de Alemania. Se puede suponer que todos estos sobrevivieron hasta la finalización de la guerra. Los 38 restantes arribaron a Suiza y de ahí, tras revisaciones y tratamiento sanitario, fueron trasladados, vía Marsella, al campo de refugiados Jean D'Arc en Philipville, Argelia.

Otros dos trenes conocidos como "los trenes perdidos", que llevaban, entre otros, entre 15 y 20 judíos con pasaportes ecuatorianos, partieron el 10.4.1945 y el 23.4.1945, supuestamente a Theresienstadt. Siete de ellos murieron en el camino.

Resumiendo, estos pasaportes emitidos por Muñoz Borrero postergaron la muerte de muchas decenas de personas. Los 10 judíos en Vittel vivieron durante algunos meses con la ilusión de que habían salvado sus vidas. De los 96 que llegaron a Bergen Belsen, 21 murieron por las terribles condiciones sanitarias y por la desnutrición imperante en este

\footnotetext{
${ }^{24}$ Rainer Schulze, “'Keeping very clear of any 'Kuh-Handel': The British Foreign Office and the Rescue of Jews from Bergen Belsen”, Holocaust and Genocide Studies, 19:2, fall 2005, pp. 226-251, sp. p. 236-237.
} 
campo los últimos meses de 1944 y en 1945, o en vías de liberación. De los 268 judíos que recibieron los pasaportes de Muñoz Borrero, sobrevivieron $80 .^{25}$

Después de la guerra, Manuel Antonio Muñoz Borrero no fue restituido al cuerpo diplomático de Ecuador. Permaneció en Estocolmo hasta comienzos de los años '60. En 1962 se trasladó a México donde falleció en 1976. Muñoz Borrero mantuvo en secreto su actuación para salvar judíos. En base a esta investigación y a la solicitud presentada por cinco familias de sobrevivientes y el nieto del Rabino Abraham Israel Jacobson que actuó junto a él en la emisión de pasaportes en Estocolmo, Manuel Antonio Muñoz Borrero fue reconocido en 2011 por Yad Vashem, la Autoridad de Recordación de los Mártires y Héroes del Holocausto de Israel, como Justo de las Naciones.

\section{Emisión de documentos chilenos en Rumania}

En mayo de 2012 se dirigió a la Embajada de Chile en Israel el Sr. Uly Kotzer con un pasaporte chileno, emitido en Bucarest, Rumania, el 14.1.1942, firmado por el Encargado de Negocios de Chile, Samuel del Campo. Este pasaporte fue emitido a nombre de Rosa Kiesler, esposa de su padre, y de él mismo, cuyo nombre entonces era Ulrich Kiesler. Años después Uly Kotzer encontró un segundo pasaporte a nombre de su padre Abraham Kiesler, con fecha del 8.12.1941. Uly Kotzer estaba seguro que estos pasaportes salvaron la vida de su familia al evitar su deportación del gueto de Czernowitz a Transnistria.

En base a su requerimiento de recibir mayor información sobre este diplomático, la embajada de Chile en Israel transfirió el caso a la Cancillería en Santiago para su investigación. Aquí tomó a su cargo las averiguaciones un funcionario del Ministerio llamado Jorge Schindler, quien encontró en el archivo histórico de la Cancillería un informe remitido por Samuel del Campo, representante de Chile en Rumania en los años 19411943. Este informe sobre el accionar de del Campo en la ciudad de Czernowitz, enviado el 1.1.1942, describe su actuación en defensa de ciudadanos polacos sin distinción de religión, para salvarlos de las persecuciones del gobierno rumano, y su intervención con este

\footnotetext{
${ }^{25}$ Ver tabla detallada en poder del autor.
} 
propósito ante la Oficina del Presidente del Consejo de Ministros rumano, el General Ion Antonescu. Asimismo, relata que designó como representate suyo en Czernowitz a un abogado, que intervino ante las autoridades e incluso recibía las denuncias de las personas que eran perseguidas en este lugar.

De acuerdo a este informe, Samuel del Campo logró salvar de la deportación a Transnistria a 250 familias. Su intervención a último momento logró que estas personas fueran devueltas a sus hogares y en el frente de sus casas se colocaron anuncios que las casas estaban bajo la protección del gobierno de la República de Chile. A continuación, el informe menciona que continúa protegiendo a los judíos en diferentes situaciones como cuando se intenta confiscar sus bienes. El informe finaliza con la pregunta de Samuel del Campo si sus superiores están de acuerdo con su actuación. ${ }^{26}$

Estos hechos se registraron en el territorio de Bukovina, cuya capital era Czernowitz, el cual se reintegró al dominio rumano en julio de 1941. El ejército rumano ingresó a la ciudad y tras él el Einsatzgruppe $D .{ }^{27}$ De inmediato comenzaron a registrarse pogromos y asesinatos organizados por la policía y los ejércitos. Hacia fines de ese mes se impusieron limitaciones sobre los lugares de residencia, la provisión de alimentos y demás condiciones discriminatorias.

En el mes de agosto, el gobernador de Bukovina recibió instrucciones de los alemanes de concentrar a los judíos en un gueto. El intendente de Czernowitz, Traian Popovici, intentó postergar la implementación de esta medida con la excusa que debía aprender el modo de trasladar a los judíos a guetos de acuerdo a la experiencia acumulada en Polonia y Alemania. En tanto se impusieron nuevas medidas discriminatorias sobre la vida de los judíos. El 9 de octubre la ciudad fue rodeada por el ejército rumano y al día siguiente se le entregó a Popovici un anuncio sobre la decisión del presidente General Ion Antonescu de expulsar a los judíos a Transnistria. A pesar de la oposición que presentó Popovici a la

\footnotetext{
${ }^{26}$ Archivo RREE Chile, Historia 2080, SdC a Ministro en Santiago, 1.1.1942.

${ }^{27}$ Los Einsatzgruppen son la unidad móvil de asesinato de las SS que acompañaban al ejército regular alemán en la invasión de Europa oriental a partir de junio de 1941. El Einsatzgruppe D contaba con 600 efectivos y estaba adjunto al XI Cuerpo de Ejército y operó en el sur de Ucrania y territorios adyacentes, Crime y Ciscaucasia. Ver SHOÁ - Enciclopedia del Holocausto, Jerusalén 2004, E.D.Z. Nativ Ediciones y Yad Vashem, pp. 224-226.
} 
deportación, logró salvar sólo algunos cientos de judíos que poseían profesiones requeridas para el normal funcionamiento de la ciudad. Por esta actuación para salvar a judíos de la deportación a Transnistria, que motivó su despido del cargo, fue reconocido por Yad Vashem como Justo de las Naciones en 1969.

La importancia en lograr la exención de la deportación a Transnistria era muy importante ya que, si bien es cierto que allí no había campos de exterminio, las condiciones en el camino y en los lugares a los cuales los judíos eran deportados eran deplorables y prácticamente la mayoría de los deportados murieron. ${ }^{28}$

Además de esta posibilidad de salvarse de la deportación en virtud de una profesión requerida en la ciudad, la información presentada por Samuel del Campo en su informe respecto de la decisión de la presidencia de Rumania que eximía de la deportación a los judíos que portaban ciudadanía extranjera, se ve confirmada por solicitudes presentadas al gobierno rumano en este sentido por las representaciones de Suiza y España ${ }^{29}$.

Estas circunstancias presentaron a Samuel del Campo dos opciones de salvamento: la primera se desprendía del hecho que con la invasión de Alemania a Polonia, Chile asumió en 1940 la representación de los intereses del gobierno de Polonia Libre en el exilio, ante Italia y Rumania. Gracias a esta posición, la representación chilena podía emitir pasaportes polacos a judíos que huyeron a Rumania con la invasión alemana.

La segunda opción fue la de otorgar a judíos la ciudadanía chilena para protegerlos ante la deportación. Esto fue lo que hizo para la familia Kiesler y en otros casos, aparentemente numerosos, en los cuales emitió documentos de protección y pasaportes de la República de Chile.

\footnotetext{
${ }^{28}$ Ver Pinkás Hakehilot, Rumania (Libro de las comunidades - Rumania, Hebreo), tomo 2, Yad Vashem 5740 (1980), pp. 504-507; SHOÁ - Enciclopedia del Holocausto, p.174.

${ }^{29}$ Ver Archivo Yad Vashem (AYV) Colección de documentación de Rumania (carpeta del Ministerio del Exterior), JM/13732 pp. 27-28 (carta de José Rojas y Moreno, representante de España en Rumania, 5.2.1942, donde destaca que judío portadores de la ciudadanía española están exentos de la deportación); ídem, pp. 276277 (carta del consulado de Suiza que anuncia que está prohibido exigir un impuesto especial de ciudadanos extranjeros debido a su origen. Aparentemente se refería a judíos con ciudadanía polaca); ídem, pp. 151-152 (cartas de la representación de Suiza en Rumania, 26.10.1943 y 2.11.1943, en las que se anuncia que está prohibido registrar como judíos a ciudadanos de países extranjeros).
} 
Esta acción, llevada a cabo en 1942 y que está documentada en los archivos del Ministerio del Exterior de Rumania y en el distrito (oblast) Czernowitz en Ucrania, se realizó contados meses después de las actuaciones descriptas por Samuel del Campo en su informe al ministerio en Santiago.

En la segunda semana de junio de 1942 el gobernador de Bukovina Calotescu ordenó nuevas deportaciones de judíos de Czemowitz a Transnistria, con el pretexto que ellos eran refugiados polacos improductivos, sospechosos de ser comunistas y que no servían a los intereses del país. En esos días, a partir del comienzo del mes de junio, Samuel del Campo comenzó su gestión para salvar a los judíos polacos que poseían pasaportes o documentos de protección chilenos. Se dirigió al Departamento de Administración y Justicia del Ministerio del Exterior rumano con la demanda que no se deporte a estos judíos y que sus bienes no estén sujetos a ninguna confiscación.

En sus gestiones ante el Ministerio del Exterior rumano, Samuel del Campo emitió certificados de ciudadanía en castellano, rumano y alemán; presentó listas con cerca de 620 nombres de judíos que contaban con la protección chilena; probablemente muchos de ellos y muchos otros judíos polacos en Czernowitz que habían sido deportados a Transnistria, poseían pasaportes chilenos y Samuel del Campo exigió que se confeccionaran listas de los bienes que les expropiaron ${ }^{30}$; el representante de Samuel del Campo en Czernowitz, el abogado Grigore Szymonowicz se dirigió al gobernador Calotescu, con la demanda de que se protegiera a las personas que contaban con la protección de la República de Chile. ${ }^{31}$

Es difícil determinar cuáles fueron los resultados concretos del accionar de Samuel del Campo en el salvamento de judíos. Hasta ahora no se han encontrado nuevos testimonios de sobrevivientes gracias a los documentos emitidos por él, y los únicos documentos que se poseen son los dos pasaportes preservados hasta el presente por Uly Kotzer.

Sin embargo, una prueba contundente de esta emisión de pasaportes y documentos de protección para el salvamento de judíos, se puede encontrar en el planteo realizado por el

\footnotetext{
${ }^{30}$ AYV, Colección de documentos de Rumania (expediente del Ministerio del Exterior rumano), JM/13735, pp. $12-42$.

${ }^{31}$ AYV, Colección de documentos del distrito de Czernowitz, Ucrania, JM/11345, pp. 10-11.
} 
Ministerio del Exterior suizo, para rechazar la designación de Samuel del Campo como cónsul general en Zurich, cuando tuvo que abandonar Rumania a mediados de 1943. Los suizos fundamentaron este rechazo con la argumentación que Samuel del Campo había entregado pasaportes en forma ilegal y a judíos. ${ }^{32}$

32 Ver Archivo de la cancillería suiza en Berna, Schweizarisches Bundesarchiv (BAR), exp. E2001D\#1000/1553\#1798*, memorando interno cancillería suiza firmado por Weber 20.4.1943; Legación de Chile en Berna a Weber, 21.4.1943; de Weck a Weber, 1.5.1943, 2.5.1943; Memorando interno cancillería suiza, 6.5.1943; Cancillería suiza a Legación chilena en Berna, 24.5.1943. Sobre el caso en torno a Roberto Grief ver A-Ch, Legación Chile en Suiza, exp. 2166, tel. Morla Lynch en Berna a Ministerio en Santiago, 26.7.1943. 


\section{Bibliografía}

Archivo de la Cancillería Suiza en Berna, Schweizarisches Bundesarchiv (BAR), exp. E2001D\#1000/1553\#1798*, memorando interno cancillería suiza firmado por Weber 20.4.1943; Legación de Chile en Berna a Weber, 21.4.1943; de Weck a Weber, 1.5.1943, 2.5.1943; Memorando interno cancillería suiza, 6.5.1943; Cancillería suiza a Legación chilena en Berna, 24.5.1943. Sobre el caso en torno a Roberto Grief ver A-Ch, Legación Chile en Suiza, exp. 2166, tel. Morla Lynch en Berna a Ministerio en Santiago, 26.7.1943.

Archivo Histórico del Ministerio de Relaciones Exteriores, Asunción, Paraguay, DACyL 394. Carta del Cónsul General del Paraguay en Zurich al Jefe de la Sección Consular del Ministerio de Relaciones Exteriores, Asunción, 24.5.1941.

Archivo Nacional Suizo. Informe del Cónsul General de Suiza en Buenos Aires al Jefe de su Departamento en Berna, 10.4.1940, en Swiss Bundesarchiv (Archivo Nacional suizo), Consulado de Paraguay en Ginebra, E2200.79-01\#1970/171\#6*.

Archivo RR.EE. Chile, Historia 2080, SdC a Ministro en Santiago, 1.1.1942.

Archivo Yad Vashem (AYV). Colección de documentación de Rumania (carpeta del Ministerio del Exterior), JM/13732 pp. 27-28, pp.276-277, pp.151-152.

Entrevista a Lic. Judith Riquelme sobre documentos atesorados en el Archivo Histórico del Ministerio del Exterior de Chile.

Gleizer, D. (2000). México frente a la inmigración de refugiados judíos: 1934-1940. Ciudad de México: El Colegio de México.

Kranzler, D. (2000). The man who stopped the trains to Auschwitz: George Mantello, El Salvador and Switzerland finest hour. Nueva York: Syracuse University Press.

Milgram, A. (ed) (2003). Entre la aceptación y el rechazo - América Latina y los refugiados judíos del nazismo. Jerusalén: Instituto Internacional de Investigación del Holocausto, Yad Vashem. 
Morse, A. (1998). While Six Million Died - A Chronicle of American Apathy. Nueva York: The Overlook Press.

Raicher, R. (2003). Uruguay, la comunidad israelita y el pueblo judío. Montevideo: Universidad Hebrea de Jerusalen $\backslash$ Universidad de la Republica.

Rodríguez, J. (2012). El Tercer Reich visto por Torre Tagle - Crónicas diplomáticas peruanas de la Segunda Guerra Mundial. Lima: Asociación de Funcionarios del Servicio Diplomático del Perú.

SHOÁ - Enciclopedia del Holocausto (1980). Jerusalem: Yad Vashem.

Schulze, R. (2005). Keeping very clear of any 'Kuh-Handel': The British Foreign Office and the Rescue of Jews from Bergen Belsen. Holocaust and Genocide Studies, 19 (2), fall.

Shulman, A. (1982). The Case of Hotel Polski - An account of one of the most enigmatic episodes of World War II. New York: Schocken.

Zadoff, E. (red.) (2004). SHOÁ - Enciclopedia del Holocausto. Jerusalén: Nativ Ediciones. 